\title{
Near Infrared High Angular Resolution Observations of Stars and Circumstellar Regions by Lunar Occultations
}

\author{
T.Chandrasekhar, N.M.Ashok and Sam Ragland \\ IR Astronomy Area, Physical Research Laboratory \\ Ahmedabad 380 009, India
}

The high angular resolution technique of lunar occultations enables one dimensional source structure in the direction of occultation to be extracted from the observed fringe pattern after detailed analysis taking into account the frequency response of the detection system, the optical filter bandwidth and the telescope size. A program of observing lunar occultations in the near infrared from $1.2 \mathrm{~m}$ telescope at Gurushikhar, Mt Abu, India $\left(72^{\circ} 47^{\prime} \mathrm{E}, 24^{\circ} 39^{\prime} \mathrm{N}\right.$, $1680 \mathrm{~m}$ ), is currently being pursued. Several occultations have been successfully observed in $\mathrm{K}$ band $(2.2 \mu \mathrm{m})$ including a day time event. The instrument used was a InSb based infrared high speed photometer, the details of which are given in a earlier paper (Ashok N.M., Chandrasekhar T. and Sam Ragland, 1994, Experimental Astronomy, 4, 177).

Table 1 lists the angular size values in milliarcsecond (mas) derived from the occultation measurements. In some cases the values represent upper limits only.

TABLE 1: Results from occultation light curves

\begin{tabular}{|c|c|c|c|c|c|}
\hline \multirow[t]{2}{*}{ Sl. No. } & \multirow[t]{2}{*}{ Source } & \multirow[t]{2}{*}{ Date } & \multicolumn{2}{|c|}{ Angular Diameter (mas) } & \multirow[t]{2}{*}{ Remarks } \\
\hline & & & measured & $\begin{array}{c}{ }^{1} \text { From } \\
\mathrm{F}_{v} \text { Vs }[\mathrm{V}-\mathrm{K}]_{0}\end{array}$ & \\
\hline 1 & IRC 10013 & $26 \operatorname{Dec} 90$ & ${ }^{2} 4.2 \pm 0.5$ & 3.0 & Possibily extended \\
\hline 2 & IRC 30094 & 22 Feb 91 & ${ }^{2} 3.0 \pm 0.5$ & 2.5 & $\begin{array}{l}\text { Large Polarisation in R - } \\
\text { Circumstellar Shell? }\end{array}$ \\
\hline 3 & IRC 20190 & 22 Feb 91 & $2.6 \pm 0.5$ & 2.1 & \\
\hline 4 & IRC 20200 & 25 Mar 91 & $3.3 \pm 0.3$ & 3.4 & $\begin{array}{l}\text { 3.1mas in K } \\
\text { (Ridgway, 1982) }\end{array}$ \\
\hline 5 & IRC 00198 & 17 Mar 92 & ${ }^{2} 2.9 \pm 0.3$ & 1.8 & $\begin{array}{l}<2 \text { mas in V } \\
\text { (Beavers, 1978) }\end{array}$ \\
\hline 6 & IRC 20169 & 4 Feb 93 & ${ }^{2} 1.8 \pm 0.3$ & 2.2 & $\begin{array}{l}\text { 1.8mas in } \mathrm{K} \\
\text { (Ridgway, 1982) }\end{array}$ \\
\hline
\end{tabular}

${ }^{1}$ Modified Barnes-Evans relation

${ }^{2}$ Most likely an upperlimit

Comparison of angular size derived from our analysis with those from a modified BarnesEvans relationship yields a reasonable level of agreement within errors. Extension of the occultation program to longer wavelengths and fainter stars at the $1.2 \mathrm{~m}$ Gurushikar telescope are in progress.

Useful comments and suggestions from A. Richichi are also gratefully acknowledged. This work was supported by the Department of Space, Government of India. 